\title{
DA CONSTRUÇÃO DO ESTEREÓTIPO DE SELVAGEM À REPRESENTAÇÃ̃O DO INDÍGENA BRASILEIRO NO LIVRO DIDÁTICO DE HISTÓRIA
}

\author{
Roberta Fernandes Santos ${ }^{1}$
}

Resumo: Este artigo aborda a maneira como se construiu o estereótipo de selvagem, fato responsável por negar aos indígenas seu direito à diferença e apagá-los como sujeitos de nossa história. Aborda também o revisionismo histórico das décadas de 1980 e 1990, destacando a Constituição de 1988 como responsável por recolocar o indígena na história, garantindo sua cidadania e reconhecendo seu direito à diversidade. Mais tarde, numa tentativa de superar estereótipos, foi aprovada a Lei $\mathrm{n}^{\mathrm{o}} 11.645 / 08$, passando a ser obrigatório o ensino de história e cultura indígena nas escolas brasileiras. Nesse sentido, analisaremos uma coleção de livros didáticos para o Ensino Médio produzida em 2016, observando como é representada a cultura indígena nesses livros e verificando, em que medida, os antigos estereótipos estão sendo superados e dando lugar a um novo olhar sobre o indígena brasileiro.

Palavras-chave: Povos indígenas. História indígena. Lei 11.645/08. Livro didático.

\section{FROM THE CONSTRUCTION OF THE STEREOTYPE OF THE SAVAGE TO THE REPRESENTATION OF THE BRAZILIAN INDIGENOUS IN THE HISTORY TEXTBOOK}

\begin{abstract}
This article discusses the way in which the stereotype of the savage was built, a fact responsible for denying the Indians their right to difference and erasing them as subjects in our history. It also addresses the historical revisionism of the 1980s and 1990s, highlighting the 1988 Constitution as responsible for putting indigenous people back in history, guaranteeing their citizenship and recognizing their right to diversity. Later, to overcome stereotypes, Law 11.645 / 08 was passed, making it mandatory to teach indigenous history and culture in Brazilian schools. In this sense, we will analyze a collection of textbooks for high school produced in 2016, observing how the indigenous culture is represented in these books and verifying, to what extent, the old stereotypes are being overcome and giving way to a new look at the Brazilian indigenous.
\end{abstract}

Keywords: Indigenous peoples. Indigenous history. Law 11.645 / 08. Textbook.

\section{DE LA CONSTRUCTION DU STÉRÉOTYPE DU SAUVAGE À LA REPRÉSENTATION DE L'INDIGÈNE BRÉSILIEN DANS LE MANUEL D'HISTOIRE}

Resumé: Cet article traite de la manière dont le stéréotype du sauvage s'est, fait responsable de nier aux Indiens leur droit à la différence et de les effacer en tant que sujets de notre histoire. Il aborde également le révisionnisme historique des années 80 et 90, mettant en évidence la Constitution de 1988 comme responsable de remettre les peuples autochtones dans l'histoire, de garantir leur citoyenneté et de reconnaître leur droit à la diversité. Plus tard, pour tenter de surmonter les stéréotypes, la loi 11.645 / 08 a été adoptée, rendant obligatoire l'enseignement de l'histoire et de la culture autochtones dans les écoles brésiliennes. En ce sens, nous analyserons une collection de manuels pour le lycée produite en 2016, en observant comment la culture autochtone est représentée dans ces livres et en vérifiant, dans quelle mesure, les vieux stéréotypes sont surmontés et donnant lieu à un nouveau regard sur l'indigène brésilien.

Mots-clés: Peuples autochtones. Histoire autochtone. Loi 11.645 / 08. Manuel scolaire.

\footnotetext{
${ }^{1}$ Graduada em História e Pedagogia. Mestre em História pela PUC-SP (2009). Doutora em História pela PUC-SP (2016). Doutotanda em Educação pela USP.
} 


\section{DESDE LA CONSTRUCCIÓN DEL ESTEREOTIPO DEL SALVAJE HASTA LA REPRESENTACIÓN DE LOS INDÍGENAS BRASILEÑOS EN EL LIBRO DE TEXTO DE HISTORIA}

Resumen: Este artículo analiza la forma en que se construyó el estereotipo del salvaje, hecho responsable de negar a los indígenas su derecho a la diferencia y borrarlos como sujetos de nuestra historia. También aborda el revisionismo histórico de las décadas de 1980 y 1990, destacando la Constitución de 1988 como responsable de devolver a los indígenas a la historia, garantizar su ciudadanía y reconocer su derecho a la diversidad. Posteriormente, en un intento por superar los estereotipos, se aprobó la Ley 11.645 / 08, que obliga a enseñar historia y cultura indígena en las escuelas brasileñas. En este sentido, analizaremos una colección de libros de texto producidos en 2016, observando cómo la cultura indígena está representada en estos libros y verificando, en qué medida, los viejos estereotipos se están superando y dando lugar a una nueva mirada sobre el indígena brasileño.

Palabras-clave: Pueblos indígenas. Historia indígena. Ley 11.645 / 08. Libro didáctico.

\section{A criação do estereótipo do selvagem}

O expansionismo marítimo ibérico marcou o início de um longo processo de contato entre os povos do chamado "Velho Mundo" e as populações nativas do continente americano. Movidos pela curiosidade e promessa de enriquecimento rápido e fácil, os europeus promoveram incessantes buscas por metais e pedras preciosas e por produtos naturais que pudessem ser aproveitados para movimentar o comércio na Europa.

Os europeus que vieram ao Novo Mundo adotaram a escrita dos relatos da conquista permeada por elementos "maravilhosos". Calcados em suas experiências literárias anteriores e diante de uma realidade tão inusitada, a produção escrita sobre a conquista esteve inteiramente povoada de seres mitológicos, monstros, fantasias, lugares extraordinários e, principalmente, riquezas incalculáveis, demonstrando o olhar europeu sobre a América e transformando aquela experiência em algo inteligível para seus leitores.

Adone Agnolin (2007) demonstrou que, durante o período colonial, os encontros culturais entre os europeus e os ameríndios, foram pautados pela mentalidade do homem renascentista que buscava fundir sua herança clássica com as novas descobertas e invenções do período. Para os europeus, foram os gregos e romanos antigos os pioneiros em encarar a alteridade dita "selvagem", dessa forma, a releitura dos textos da Antiguidade Clássica serviria para a construção de um modo de proceder diante do outro, classificado, então, como selvagem.

Para Giucci (1992), o continente americano representava para o europeu um espaço real, embora permeado de elementos idealizados. Este espaço precisava ser 
dominado e incorporado, não apenas no imaginário, mas também em seus domínios coloniais. Pautados por esse objetivo, os europeus deram início a um projeto de conquista e colonização do Novo Mundo que visava transformar a natureza americana em mercadoria e os habitantes nativos em mão-de-obra.

As atribuições de nomes europeus para a natureza e para as populações nativas eram parte desse processo de colonização empreendida pelos conquistadores na América:

Entraram e tomaram posse de tudo: mudaram os nomes dos acidentes geográficos a seu bel-prazer, deram nome a rios e montanhas; e até mesmo os povos que aqui viviam passaram a ser chamados de "índios", numa atitude homogeneizante e facilitadora da escravidão para conseguir a mão-de-obra de que necessitavam com o objetivo de ter sucesso rápido na busca por riquezas. (KAUSS, 2011, p. 64)

Tanto quanto o fator econômico, o fator religioso também foi usado como motivador das conquistas, pois os europeus acreditavam no pretexto universalista da religião cristã. Portanto, a colonização da América também daria a estes homens a oportunidade de levar a "verdadeira" religião aos "selvagens" do Novo Mundo. Nesta perspectiva, as missões religiosas, atreladas ao projeto colonial, seriam as responsáveis por tirar o nativo da "barbárie" e inseri-lo no mundo "civilizado"; para isso, era necessário abolir os costumes indígenas e destruir suas culturas.

Assim, durante o período colonial, as culturas indígenas foram inferiorizadas, seus sistemas de organização social foram desmerecidos, seus saberes foram desconsiderados, as vozes de seus povos foram sufocadas e estas populações foram submetidas a sucessivos processos de assimilação.

No século XIX, mesmo após a independência, a ideia de inferioridade que o europeu agregou às culturas indígenas continuou em voga. A historiografia do período corroborava o projeto de construção de um Estado brasileiro uniforme, cujo principal objetivo era apagar a diversidade que caracterizava - e ainda caracteriza - a população brasileira. Neste projeto de nação, não havia espaço para a pluralidade étnica; sendo assim, os povos indígenas foram "invisibilizados" da nossa história, cabendo-lhes apenas um papel secundário e idealizado no nosso passado.

Durante a primeira metade do século $\mathrm{XX}$, a historiografia brasileira ainda encarava a presença indígena na história nacional como um "problema" sem solução. Apesar da nova roupagem republicana, os autores do período foram responsáveis por legitimar as tendências homogeneizantes ao exaltarem a mestiçagem como uma 
característica peculiar da identidade nacional. Nascia o mito da "democracia racial" que passaria a exaltar a formação mestiça da cultura brasileira como fruto da interação entre as culturas europeias, indígenas e africanas.

Novamente os conflitos e a diversidade cultural foram apagados em prol de um projeto de monoculturalismo homogeneizador: "o ocultamento da diversidade produz a imagem do brasileiro cordial, que trata todos com igualdade, ignorando deliberadamente as suas nítidas e contundentes diferenças" (SILVA, 2011, p. 11).

\section{A questão indígena a partir da década de 1980: o revisionismo histórico}

Embora tenham sido compelidas a constantes processos assimilacionistas, as sociedades e as culturas indígenas resistiram e sobreviveram. John Monteiro (1999) foi um dos primeiros historiadores a considerar a perspectiva indígena ao mostrar que essas populações forjaram espaços próprios de atuação dentro do sistema colonial. John Monteiro afirmou que a resistência indígena se deu mais pela abertura para as inovações do que pela violência, o que permitiu a sobrevivência física e cultural dessas populações.

A partir dessa perspectiva, muitas pesquisas estão sendo feitas e os trabalhos que se têm produzido buscam recolocar os indígenas como protagonistas de sua história, como povos que lutaram e ainda lutam pelo reconhecimento de suas culturas e pelo direito à diferença. "Dos bastidores ao palco" foi a expressão utilizada pela historiadora Maria Regina Celestino de Almeida (2010) ao abordar as transformações nos estudos sobre os indígenas que passam a ser reconhecidos como sujeitos ativos da História do Brasil e protagonistas de suas próprias trajetórias históricas (ALMEIDA, 2010, p. 13).

A visão inferiorizada dos indígenas também foi legalmente superada pela Constituição de 1988, que reconheceu a diversidade e garantiu às populações indígenas o direito à diferença. Sabemos que da criação da lei à formação de uma nova mentalidade, há uma enorme distância, entretanto, já temos a clareza que, para a compreensão de uma sociedade multicultural, se faz necessário resolver os problemas ocasionados por anos de opressão e discriminações. Acreditamos que o ponto de partida para solucionar esses problemas esteja na educação:

Políticas públicas bem formuladas e estruturadas podem avançar e modificar situações cristalizadas como as desigualdades entre os cidadãos brasileiros e regiões do país. Sabemos que a educação não é suficiente para mudar essa realidade, mas sem ela nada se moverá. (CUPOLILLO, MAJEROEICZ E PLASA SILVA, 2011, p. 95) 
Ao longo do século XX, a educação brasileira foi estruturada como um instrumento de regulação social, fortemente vinculada ao ideário civilizatório e reforçando o padrão homogeneizador. Muitas gerações de brasileiros foram formadas a partir dessa perspectiva e, ainda hoje, percebemos que vigora em nossa sociedade uma visão estereotipada dos indígenas.

A criação da Lei $n^{\circ}$ 10.639/2003 - que determinou a obrigatoriedade do ensino de história e cultura afro-brasileira e africana - representou um significativo avanço no reconhecimento das diferenças. Apesar da lei marcar o florescimento de uma nova proposta pedagógica, ela se limitava em atender as demandas do movimento negro.

Em 2008, a Lei $n^{\circ} 10.639 / 2003$ foi alterada para a Lei $n^{\circ} 11.645 / 2008$ e passou a incluir a obrigatoriedade do ensino de história e cultura indígena. Não podemos deixar de mencionar que a aprovação dessa lei foi uma resposta aos anos de luta dos movimentos indígenas que, desde há muito, reclamavam o reconhecimento de suas trajetórias históricas na construção da nação e da cultura brasileira:

É justamente a regra que permite que seja feita violência à violência e que uma outra dominação possa dobrar aqueles que dominam. Em si mesmas, as regras são vazias, violentas, não finalizadas; elas são feitas para servir a isto ou àquilo; elas podem ser burladas ao sabor da vontade de uns ou de outros. O grande jogo da história será de quem se apoderar das regras, de quem tomar o lugar daqueles que as utilizam, de quem se disfarçar para pervertê-las, utilizá-las ao inverso e voltá-las contra aqueles que as tinham imposto; de quem, se introduzindo no aparelho complexo, o fizer funcionar de tal modo que os dominadores encontrar-se-ão dominados por suas próprias regras. (FOUCALT, 2013, p. 6970)

Apenas após ser pressionado pela sociedade civil organizada, o Estado estabeleceu políticas de promoção da igualdade com o objetivo de alterar a situação desfavorável das chamadas minorias sociais, como é o caso dos indígenas. Esse processo não está acontecendo sem resistências, pois os grupos e movimentos indígenas reivindicam o direito de reconhecimento de suas diferenças como meio de questionar as relações de poder e subverter a lógica da dominação.

Embora a Lei $n^{\circ} 11.645 / 08$ represente uma enorme conquista para a causa indígena, por si só ela não garante a solução do problema. Para que haja a consolidação dos ideais propagados pela Lei 11.645/08, não basta a sua mera existência, é preciso que ela se desdobre em ações e atitudes democráticas, cidadãs, igualitárias, emancipadoras e autônomas. 
E o lugar privilegiado para que isso ocorra é a escola, pois é onde o estudante pode participar do processo de construção do conhecimento pautado em novos paradigmas, do reconhecimento e da promoção de outros valores e visões de mundo que não apenas o produzido pela cultura ocidental hegemônica.

\section{A construção de novos valores: educação, ensino de História e livro didático}

Em A crise da educação, Hanna Arendt (2005) afirma que a escola é o lugar onde o indivíduo é preparado para renovar o mundo, o que implica, antes, conhecer o mundo como ele é. Temos aí a grande contradição do papel da escola: ao mesmo tempo em que ela é responsável pela transmissão dos conhecimentos, saberes e valores validados pela sociedade, a escola também se constitui em um espaço de construção de novos saberes e de reinvenção das tradições, de modo que ela possa atender as demandas mais atuais da sociedade que a gesta.

Forquin (1993), ao debater sobre a função da escola como transmissora da tradição, afirma que não há uma cultura, única e legítima, a ser transmitida; a cultura transmitida no âmbito escolar pode ser entendida como uma seleção de saberes. Nesse aspecto, Forquin aponta para uma dúvida do que merece ser verdadeiramente ensinado.

Inés Dussel trata sobre a possibilidade da existência de uma cultura comum a todos, sendo que esse seria o maior desafio da escola nos dias de hoje: “[...] estruturar uma ideia de cultura comum que possa ser transmitida e compartilhada, que leve em conta as injustiças e privilégios do passado e que ao mesmo tempo proponha outras inclusões [...]" (DUSSEL, 2007, p. 359).

Nos dias atuais, a função de transmissão cultural, que já não é exclusiva da instituição escolar, também se encontra dividida entre os meios de comunicação e a internet, que ressaltam, sobretudo, o individualismo como valor, tornando cada vez mais questionável a possibilidade de construção de uma cultura comum.

Diante desse impasse em que a escola é colocada tanto na função de transmissora da tradição como renovadora dela, é importante que, principalmente no estudo da História, haja um lugar para o debate sobre o passado e o presente. Conforme Dussel: "nesse cruzamento e rearticulação de temporalidades, pode haver lugar para uma transmissão que não seja apresentada como repetição mecânica de uma história, mas como a passagem de uma tradição que se renova e se redefine com cada nova geração" (DUSSEL, 2007, p. 360). 
Assim como afirmou Marc Bloch (2001, p. 54-55), a história é uma ciência cujo objeto de estudo é o homem, mas não só isso, a história deve preocupar-se em entender o homem inserido na duração, ou seja, o homem no tempo. Também como nos alerta Certeau (1982), é fundamental entender que a história olha para o homem no passado, mas, esse olhar, inexoravelmente parte do presente. Isso significa que nossa compreensão das experiências humanas anteriores é necessariamente filtrada pelas questões do tempo presente.

É urgente a necessidade de que ocorra na escola um avanço significativo na construção de novos paradigmas que colaborem para uma educação que respeite a diversidade cultural e considere os processos históricos e as relações de poder que perpassam as contínuas reelaborações culturais que ocorrem em nossa sociedade.

Infelizmente, não foi assim que muitas gerações foram formadas. Ainda hoje é possível recorrermos a uma série de representações ao nos referirmos ao indígena e percebermos que essas representações são baseadas em uma ideia de passado congelado, no qual as populações indígenas são vistas apenas como povos nativos. Para muitos, os indígenas de hoje seriam descaracterizados, pois se transformaram e não mais correspondem às representações.

Essa visão de mundo tem severas implicações para o ensino de História nas escolas. Que história queremos ensinar? De que indígena tratar? Entendemos a dificuldade em desconstruir estereótipos tão arraigados, mas afirmamos que o ensino da História é o lugar privilegiado para que isso ocorra.

Também se faz necessário um olhar para os livros didáticos - especialmente os de História - que, apesar dos avanços da tecnologia e das mídias digitais, continua sendo um instrumento importante no processo de ensino e aprendizagem. Na maioria das escolas públicas no país, o livro didático é, muitas vezes, o único material disponível para estudantes e professores.

Neste artigo, o livro didático também é entendido e utilizado como fonte histórica, um documento que revela espaços políticos e disputas sociais e não um livro cheio de verdades que são ensinadas às gerações mais novas. É necessário entender o livro didático como uma fonte histórica produzida por determinada sociedade e, portanto, carregada das representações da realidade da sociedade que o produziu. Conforme alerta Jacques Le Goff: 
O documento não é inócuo. É [...] o resultado de uma montagem, consciente ou inconsciente, da história, da época, da sociedade que o produziram, mas também das épocas sucessivas durante as quais continuou a viver, talvez esquecido, durante as quais continuou a ser manipulado, ainda que pelo silêncio. $\mathrm{O}$ documento é uma coisa que fica, que dura, e o testemunho, o ensinamento (para evocar a etimologia) que ele traz devem ser em primeiro lugar analisados desmistificando-lhe o seu significado aparente. O documento é monumento. Resulta do esforço das sociedades históricas para impor ao futuro - voluntária ou involuntariamente - determinada imagem de si próprias. No limite, não existe um documento verdade. Todo documento é mentira. Cabe ao historiador não fazer o papel de ingênuo. (LE GOFF, 1984, p. 103)

Os povos indígenas e sua cultura estão presentes nos livros didáticos de História. Nos interessa agora entender de que maneira eles são representados e em que medida eles são reconhecidos enquanto agentes históricos.

\section{A representação do indígena brasileiro no livro didático de História}

Atualmente, no Brasil, todos os livros didáticos utilizados nas escolas devem ser aprovados pelo Ministério da Educação (MEC). Até 2018, para que essa aprovação ocorresse, os livros didáticos deveriam estar adequados aos Parâmetros Curriculares Nacionais PCN (1999); para o Ensino Médio, ainda havia que se considerar a Matriz de Referências do Enem (2009). Para as escolas públicas, a distribuição dos livros didáticos é financiada pelo Fundo Nacional de Desenvolvimento da Educação (FNDE), através do Programa Nacional do Livro Didático (PNLD).

Analisaremos nesse artigo, uma coleção de livros didáticos de História, aprovada no PNLD 2018 do Ensino Médio, sendo este o último realizado para o segmento. Foram 13 coleções de livros didáticos de História aprovadas no PNLD 2018. Selecionamos a $2^{\text {a }}$ edição da Coleção História - sociedade \& cidadania $^{2}$, de Alfredo Boulos Júnior, composta por 3 volumes (uma para cada série do Ensino Médio) e publicada pela editora FTD.

É interessante destacar que, o Manual do Professor, além de conter as respostas para as atividades propostas no livro, contém também um encarte com alguns materiais de apoio, com textos sobre as concepções teórico-metodológicas adotadas pelo autor em sua obra e textos complementares sobre os temas tratados no livro.

No Manual do Professor desta coleção, Boulos Júnior apresenta três das correntes que, segundo ele, são as mais frequentes nas produções historiográficas atuais:

\footnotetext{
${ }^{2}$ Para este trabalho, utilizamos a versão do Manual do Professor, distribuída aos professores pela Editora FTD em 2017.
} 
O Positivismo, o Materialismo Histórico e a Nova História; e situa sua obra na Nova História:

Neste livro, pautamo-nos por alguns referenciais teóricos da Nova História, daí entendermos a História como um conhecimento em permanente construção; por isso tomamos o documento como ponto de partida e não de chegada na construção do conhecimento e, além disso, incorporamos a ação e a fala das mulheres, dos negros, dos indígenas, dos operários e de outros sujeitos históricos antes relegados ao esquecimento. (BOULOS JÚNIOR, 2016, p. 295)

Dessa forma, entendemos que o autor pensa a História como uma ciência que produz um conhecimento que está em constante transformação, respondendo sempre às demandas do tempo presente. Para ele, o documento, ou seja, a fonte histórica, é de primordial importância, sendo o ponto de partida para a construção das representações presentes em sua obra. Além disso, o autor afirma que valoriza a atuação de sujeitos históricos considerados marginalizados, como as mulheres, os negros, os indígenas e outros.

Tratando do tema "Cidadania, etnia e gênero", o autor destaca a importância da atuação dos movimentos sociais para as conquistas envolvendo a legislação (Lei $\mathrm{n}^{\mathbf{o}}$ 10639/2003 e Lei n ${ }^{\circ} 11645 / 2008$ ) e esclarece que não devemos estudar a temática afro e indígena apenas por obediência à legislação, mas também, e principalmente por contribuir para a construção da cidadania, para a educação voltada à tolerância e ao respeito ao outro, e, além disso, destaca que o estudo da matriz afro e indígena é indispensável a toda população brasileira, seja ela indígena, afro-brasileira ou não, pois é a base da construção das identidades (BOULOS JÚNIOR, 2016, p. 322-323).

Após breve explanação dos pressupostos teóricos apresentados pelo autor, partimos para a análise dos livros didáticos de sua autoria. Observamos que a temática indígena é abordada nos 3 volumes da coleção. Para facilitar a leitura, analisaremos separadamente cada volume, para depois construirmos um olhar mais amplo sobre toda a coleção.

No Volume 1, direcionado à primeira série do Ensino Médio, a temática indígena é abordada em 3 dos 14 capítulos.

No Capítulo 1 - História, cultura, patrimônio e tempo -, no item "A valorização das matrizes africana e indígena" o autor usa, para exemplificar a matriz indígena, a Arte Kusiwa, própria dos povos indígenas Wajãpi, do Amapá (em 2003 recebeu da Unesco o título de Patrimônio Cultural Imaterial da Humanidade). O autor utiliza 5 
linhas para explicar o que é a arte Kusiwa e usa uma imagem de um cesto produzido a partir da utilização dessa técnica (BOULOS JÚNIOR, 2016, p. 18).

No Capítulo 2 - A aventura humana: primeiros tempos -, no item "O que se sabe sobre os paleoíndios?", em 5 páginas, o autor trata dos primeiros grupos humanos que se estabeleceram nas terras do que hoje é o Brasil, além das suas formas de adaptação, sobrevivência e invenções tecnológicas. $\mathrm{O}$ autor se utiliza de imagens de pontas de flechas, boleadeiras, sambaquis, zoólitos e cerâmica para demonstrar que os primeiros povos que habitaram o território brasileiro souberam aproveitar a natureza para a garantia de sua sobrevivência e a transformaram, adaptando-se às condições locais e aprimorando as técnicas de coleta, pesca e caça (BOULOS JÚNIOR, 2016, p. 40-44).

No Capítulo 13 - Tempos de reis poderosos e impérios extensos - no subtítulo “As grandes navegações", o autor prioriza as questões econômicas e políticas do processo e aborda a temática indígena no exercício "Cruzando fontes", em que propõe que o estudante faça uma comparação entre a fonte 1 - a imagem da primeira missa de Victor Meirelles - e a fonte 2 - um trecho retirado do livro "A passagem do século: 1480-1520: as origens da globalização" em que Serge Gruzinski fala sobre a realização da primeira missa. A atividade pede que os estudantes comparem as duas fontes, indiquem a que acham mais convincente e expliquem o porquê da escolha. (BOULOS JÚNIOR, 2016, p. 261). É interessante observar que não há menção sobre o choque entre as culturas europeia e indígena ocorrido durante o período das chamadas grandes navegações.

No Volume 2, direcionado à segunda série do Ensino Médio, a temática indígena é abordada também em 3 dos 14 capítulos, porém, neste volume, a temática é trabalhada de forma um pouco mais extensa.

Logo na Unidade 1 - Nós e os outros: a questão do etnocentrismo -, o primeiro capítulo trata exclusivamente da América indígena. A página inicial do capítulo traz um mapa representando a divisão da América por grupos linguísticos indígenas no século XVI e, ao redor do mapa, figuras de indígenas representando as etnias que serão trabalhadas ao longo do capítulo. No mapa, o autor destaca apenas 13 grupos linguísticos, dessa forma, a enorme diversidade cultural dos povos indígenas americanos fica restrita a 13 grupos linguísticos. As imagens ao redor do mapa nos mostram que, no capítulo, o autor privilegiará o estudo dos povos astecas, maias, incas e tupis. Veremos brevemente como que o autor retrata cada uma dessas populações. 
Sobre os astecas há um destaque para as conquistas e para a dominação de outros povos que foram realizadas antes da invasão dos espanhóis. Também chama a atenção para a existência de uma sociedade estratificada e um elaborado sistema de cobrança de impostos. O mais interessante é que a cidade de Tenochtitlán é representada por um afresco de Diego Rivera, que retrata toda a grandiosidade das construções e revela as atividades produtivas realizadas no local (BOULOS JÚNIOR, 2016, p. 13-14).

Sobre os maias, o autor destaca a composição hierarquizada da sociedade e compara as cidades maias com as cidades-estados gregas. Aqui também o autor utiliza uma imagem para retratar a cidade de Palenque; é uma foto tirada em 2011, que mostra a grandiosidade e a sofisticação das construções maias (BOULOS JÚNIOR, 2016, p. 15-17).

Sobre os incas, o autor trata da expansão do império e das conquistas de outras populações realizadas até a segunda década do século XVI. A imagem utilizada pelo autor para representar a civilização inca é uma foto de Machu Picchu, tirada em 2013 (BOULOS JÚNIOR, 2016, p. 18-20).

Após tratar dos astecas, maias e incas, o autor passa para o item "Indígenas nas terras onde hoje é o Brasil". Destacamos as primeiras palavras do autor sobre o assunto:

O conhecimento acumulado sobre os indígenas do Brasil é pouco disseminado entre nós, o que leva muitas pessoas a reproduzir juízos extraídos do senso comum. Um equívoco, por exemplo, é ver os povos indígenas como parados no tempo, como muitas vezes vemos em noticiários, jornais e revistas. As sociedades indígenas passaram por mudanças significativas. São histórias de milhares de anos, marcadas por confrontos e alianças, deslocamentos, conquistas e perdas; enfim uma história tão movimentada e interessante quanto a de outros povos. (BOULOS JÚNIOR, 2016, p. 22)

Observamos que o autor mostra o dinamismo das culturas indígenas e destaca a importância da compreensão desse processo para a superação dos estereótipos que prendem as populações indígenas ao passado e desconsideram a sua historicidade.

Logo após essa explanação, o autor trata das diferenças entre os povos indígenas que habitavam o território do Brasil atual e utiliza duas representações feitas por pintores europeus no século XIX (BOULOS JÚNIOR, 2016, p. 22). Embora o texto que segue as imagens dê destaque para as diferenças entre as duas figuras (corte do cabelo, adornos, pintura corporal e outras), notamos que ambas as imagens são representações europeias das populações indígenas e não retratam todo o movimento de transformação das culturas que o autor ressalta no parágrafo anterior. Ainda assim, destacamos que o 
autor utiliza 7 páginas para tratar das populações indígenas brasileiras (BOULOS JÚNIOR, 2016, p. 22-28).

Ao tratar das diferenças entre os povos indígenas do Brasil, o autor destaca a questão linguística e a arte. Sobre as línguas indígenas, é interessante observar que o autor explica que as línguas são agrupadas em famílias e estas, em troncos; para exemplificar essa questão, Boulos Júnior utiliza uma tabela retirada do livro "A temática indígena na escola"3, que mostra uma comparação entre os troncos indoeuropeu e tupi (BOULOS JÚNIOR, 2016, p. 23). Já sobre a arte indígena, há um pequeno texto citando as diversas formas de se manipular os elementos da natureza, o que, segundo o autor, constitui a singularidade de cada produção tupi (BOULOS JÚNIOR, 2016, p. 24).

Além de tratar das diferenças entre as populações indígenas, o autor também apresenta, sem se alongar no assunto, algumas semelhanças entre elas: a divisão social, o uso coletivo das terras, a divisão do trabalho por sexo e idade e a socialização do conhecimento (BOULOS JÚNIOR, 2016, p. 24).

A respeito do embate com os portugueses, o autor mostra que, num primeiro momento, foram realizadas amistosamente trocas de mercadorias entre portugueses e populações indígenas. Somente a partir da década de 1530, os contatos teriam ficado mais violentos, com a captura dos nativos para o trabalho nos engenhos. Para o autor, apesar das revoltas indígenas e da resistência individual:

[...] os colonizadores acabaram vencendo pela força e conquistando para si as terras indígenas. As guerras de apresamento, as grandes fomes que geralmente acompanhavam essas guerras, a escravidão e, sobretudo, doenças, como gripe, sarampo, tuberculose e varíola, causaram a morte de dezenas de milhares de indígenas. (BOULOS JÚNIOR, 2016, p. 25)

Por fim, o autor fala sobre as lutas dos povos indígenas atualmente, organizadas tanto pelas organizações indigenistas, como por aquelas lideradas pelos próprios indígenas. Há um destaque para os avanços conquistados pelos movimentos indígenas na Constituição de 1988 (BOULOS JÚNIOR, 2016, p. 27-28).

No Capítulo 2 - Colonizações: espanhóis e ingleses na América - o autor aborda a questão da resistência indígena e a colonização dos territórios conquistados pelos espanhóis. De acordo com o autor, a resistência indígena se deu de diversas formas: prática de suicídio, revoltas, fugas individuais ou em grupos e por meio de armas. Como

\footnotetext{
${ }^{3}$ A referência utilizada é TEIXEIRA, 1988, p. 299.
} 
exemplo, o autor aponta a revolta de Túpac Amaru, que se deu entre 1532 e 1752 (BOULOS JÚNIOR, 2016, p. 35-36).

Na Unidade 2 - Diversidade e pluralismo cultural - no Capítulo 5 - Expansão e ouro na América portuguesa - há um item sobre os jesuítas, retratando-os como contrários à escravidão dos indígenas. A missão jesuítica é tratada como um espaço de proteção aos indígenas; o autor não apresenta críticas sobre esse ponto de vista (BOULOS JÚNIOR, 2016, p. 96-97).

Ainda no Capítulo 5 há os itens "As bandeiras" e "A caça aos indígenas" em que, mais uma vez, o autor afirma que as populações indígenas foram dizimadas pelos colonizadores (BOULOS JÚNIOR, 2016, p. 99-100). Há que se destacar o uso da palavra "caça". No dicionário Aurélio, "caça" recebe as seguintes significações: "Caçada. Animais caçados. Conjunto de animais que se podem caçar. Busca, perseguição.” (FERREIRA, 2010, p. 123). Destaca-se aqui que o indígena não era considerado um ser humano, mas um "espécime" a ser caçado e subordinado. Mesmo de forma inconsciente, o autor reproduz essa visão ao utilizar a palavra "caça" no subtítulo.

Na Unidade 3 - Cidadania: passado e presente -, no Capítulo 9 Independências: Haiti e América espanhola - o autor aborda o tema da revolta de Túpac Amaru, que ocorreu entre 1780 e 1781 (BOULOS JÚNIOR, 2016, p. 178-179). Destacamos que não há referências específicas sobre resistências indígenas em território brasileiro.

No último volume da coleção, o Volume 3, destinado aos alunos da terceira série do Ensino Médio, a questão indígena é abordada apenas uma vez. Na Unidade 3 Movimentos sociais - no Capítulo 11 - O Regime Militar - no subtítulo - A Constituinte e a nova Constituição. O autor cita a participação do Movimento Indígena e sua importância para a conquista dos direitos expressos na Constituição de 1988 (BOULOS JÚNIOR, 2016, p. 221).

Após observar todo o conjunto da obra, fica evidente que o autor privilegia os processos políticos e econômicos, relegando a um segundo plano as questões sociais e culturais. Como nos mostram Silva e Lemos (2013, p. 67), desde a década de 70, a historiografia apresenta uma nova forma de ver as relações sociais e as dimensões culturais, entendendo que as forças políticas e econômicas não se sobrepunham a elas: "afinal, a educação e as experiências educativas não se encontravam plenamente determinadas apenas pelas formas políticas, administrativas ou econômicas vividas." 
(SILVA e LEMOS, 2013, p. 73). Como vimos, a coleção analisada dá pouca atenção aos processos sociais e às questões culturais. Entretanto, sabemos que já é hora de ultrapassarmos essas representações calcadas apenas em marcos políticos e econômicos para que se consolidem análises mais atentas às relações sociais e manifestações culturais.

A temática indígena ainda é representada conforme os estereótipos, fato que pode ser constatado pela escolha das imagens que constam no livro. As populações indígenas mesoamericanas são representadas pela grandiosidade de suas construções, enquanto os indígenas brasileiros ainda são retratados nus, ornados com pinturas corporais, portando arcos, flechas e lanças e deitados em redes. Esta oposição ainda é pouco discutida na História, entretanto sua utilização reforça a dicotomia civilização X barbárie e o estereótipo de selvagem construído para designar os povos indígenas brasileiros.

Além disso, observamos na coleção analisada que a temática indígena na história do Brasil é abordada em períodos específicos: anterior à conquista europeia, no período colonial e após a ditadura militar. Não há referências à história indígena nos demais momentos da nossa história, demonstrando a invisibilidade das populações indígenas e sua negação como sujeitos da nossa história.

Outro fator importante a se destacar é que os movimentos indígenas de resistência citados no livro ocorreram em territórios de conquista espanhola. Não há menção sobre movimentos de resistência indígena no Brasil. Michel de Certeau, em suas análises sobre o Brasil, já destacava a importância de olhar para a cultura nas suas múltiplas manifestações e, sobre a resistência indígena, dava destaque para as estratégias não violentas de reapropriação cultural (VIDAL, 2005, p. 272).

Sobre os avanços alcançados na Constituição de 1988, o autor cita a participação dos movimentos indígenas na conquista dos direitos, mas não aprofunda a questão de que essas conquistas são fruto de incessantes lutas e conflitos ocorridos ao longo de toda a história das populações indígenas brasileiras.

\section{Considerações Finais}

$\mathrm{Na}$ coleção de livros didáticos aqui analisados, vimos que a abordagem da temática indígena ainda é um grande desafio. O principal obstáculo a ser superado é o de desconstruir as visões equivocadas e estereotipadas que foram produzidas ao longo dos séculos. Esse é um desafio urgente, porém de difícil execução, mesmo com a 
renovação historiográfica ocorrida a partir dos anos 1980 e os avanços legais alcançados pela Constituição de 1988 e pela Lei n.11645/08.

De um modo geral, os livros didáticos estão distantes da produção acadêmica porque tendem a construir um conhecimento próprio do cotidiano escolar. Dessa forma, os livros didáticos de História que analisamos revelam-se deficientes no tratamento da diversidade étnica e cultural existente no Brasil, especialmente em se tratando da diversidade cultural indígena.

Não se pretende que o livro didático comtemple "toda a História", que seja capaz de reunir todas as experiências de vida das populações indígenas ao longo da história do Brasil. Mas é necessário que as populações indígenas sejam historicizadas e retratadas como efetivos sujeitos de suas histórias.

\section{Referências}

\section{Fonte}

BOULOS JÚNIOR, Alfredo. Coleção História - sociedade \& cidadania. 2. ed. São Paulo: FTD, 2016.

\section{Bibliografia}

AGNOLIN, Adone. Jesuítas e Selvagens: a negociação da fé no encontro catequéticoritual americano-tupi (séc. XVI - XVII). São Paulo: Humanitas, 2007.

ALMEIDA, Maria Regina Celestino de. Os índios na história do Brasil. Rio de Janeiro: Editora FGV, 2010.

ARENDT, Hanna. Entre o passado e o futuro. Trad. de Mauro W. Barbosa. 5. ed. São Paulo: Perspectiva, 2005.

BLOCH, Marc. Apologia da história, ou, O ofício de historiador. Rio de Janeiro: Jorge Zahar, 2001.

CERTEAU, Michel de. A escrita da história. Rio de Janeiro: Forense Universitária, 2011.

CUPOLILlO, Amparo Vila, MAJEROWICZ, Nídia e SILVA, Rosana Pinto Plasa. Acesso aos cursos de graduação da Universidade Federal Rural do Rio de Janeiro: Análise crítica e comparativa dos processos de seleção e suas capacidades e limites inclusivos e democráticos. In: SISS, Ahyas e MONTEIRO, Aloísio Jorge de (orgs.). Educação e debates etnicorraciais. Rio de Janeiro: Quartet, Leafro, 2011. p. 79-96.

DUSSEL, INÉS. A transmissão cultural assediada: metamorfoses da cultura comum na escola. Cadernos de Pesquisa, v. 39, n. 137, maio/ago. 2009, p. 351-365. 
FERREIRA, Aurélio Buarque de Holanda. Mini Aurélio: o dicionário da língua portuguesa - 8 edição. Curitiba: Positivo, 2010.

FORQUIN, Jean Claude. Escola e cultura: as bases sociais e epistemológicas do conhecimento escolar. Porto Alegre: Artmed, 1993.

FOUCAULT, Michel. A Microfísica do poder. São Paulo: Graal, 2013.

GIUCCI, Guillermo. Viajantes do Maravilhoso: o Novo Mundo. São Paulo: Companhia das Letras, 1992.

KAUSS, Vera. Figurações do indígena: construindo, desconstruindo, reconstruindo a identidade brasileira nos textos literários. In: SISS, Ahyas e MONTEIRO, Aloísio Jorge de (orgs.). Educação e debates etnicorraciais. Rio de Janeiro: Quartet, Leafro, 2011, p. 63-78.

LE GOFF. Jacques. Documento / Monumento. Enciclopédia Einaudi, vol. 1, Memória História. Lisboa: Imprensa Nacional-Casa da Moeda, 1984, p. 95-106.

MONTEIRO, John Manuel. Negros da terra: índios e bandeirantes nas origens de São Paulo. São Paulo: Companhia das Letras, 1999.

SILVA, José Cláudio Sooma; LEMOS, Daniel Cavalcanti de Albuquerque. A História da Educação e os desafios de investigar outros presentes: algumas aproximações. In: FERREIRA, Marcia Serra; XAVIER, Libania; CARVALHO, Fábio Garcez de. História do Currículo e História da Educação: Interfaces e Diálogos. Rio de Janeiro: Quarter / FAPERJ, 2013. p. 61-85.

SILVA, Petronilha Beatriz Gonçalves. Aprender, ensinar e relações étnico-raciais no Brasil. In: FONSECA, Marcus Vinícius, SILVA, Carolina Mostaro Neves da; FERNANDES, Alexsandra Borges (orgs.). Relações étnico-raciais e educação no Brasil. Belo Horizonte: Mazza Edições, 2011. p. 11-38.

VIDAL, Diana Gonçalves. Michel de Certeau e a difícil arte de fazer história das práticas. In: FARIA FILHO, Luciano Mendes de (org.). Pensadores Sociais e História da Educação. Belo Horizonte: Autêntica, 2005. p. 257-284.

Artigo recebido em 19 de junho de 2020. Aprovado em 16 de novembro de 2020. 